\title{
Rehabilitative management of pelvic fractures: a literature-based update
}

\author{
Francesco Piccione (1), Maria Chiara Maccarone (2), Anna Maria Cortese (3), Guido \\ Rocca (4), Umberto Sansubrino (1), Giovanni Piran (2), Stefano Masiero (1,2)
}

(1) Department of Neuroscience, Rehabilitation Unit, University of Padova, Padova, Italy; (2) Physical Medicine and Rehabilitation School, University of Padova, Padua, Italy (3) IRCCS San Camillo Hospital, Venice, Italy; (4) Centro Regionale per la Chirurgia della Pelvi e del Bacino, ULSS 6, Veneto Region, Italy.

This article is distributed under the terms of the Creative Commons Attribution Noncommercial License (CC BY-NC 4.0) which permits any noncommercial use, distribution, and reproduction in any medium, provided the original author(s) and source are credited.

\begin{abstract}
A comprehensive rehabilitation program is required after Pelvic Fracture (PF). In a PF rehabilitation setting an effective treatment and a proper management of complications is supplied by an appropriate and reliable clinical assessment. In this literature-based update, we search on MEDLINE, EMBASE, and the Cochrane Database of Systematic reviews to find articles, scientific society guidelines and practioners experiences defining the rehabilitative management of clinically PF outcomes. Based on literature evidences and expert opinions, a set of key topics was collated to generate advices and recommendations to put into daily practice. Even if there are no high-quality evidence for rehabilitative interventions after PF in terms of duration and modality of therapy, rehabilitation setting, care pathways, and long-term functional outcomes, it is strongly recommended an early multidisciplinary intervention to improve recovery from PF.
\end{abstract}

Key Words: Pelvic; acetabular; fractures; rehabilitation.

Eur J Transl Myol 31 (3): 9933, 2021 doi: 10.4081/ejtm.2021.9933

Among fractures, Pelvic Fracture (PF) is quite rare (3$8 \%$ of total), but have high mortality rate ( 5 to $40 \%$ ). ${ }^{1,2}$ A severe PF necessitates of comprehensive rehabilitation with recovery periods affected by associated injuries, e.g. nerves lesions or urinary and intestinal dysfunctions. Effective treatments and proper monitoring of complications are usually lacking, while essential for optimal outcome. According to a recent review, surgeons define "early" the treatment between 8 hours up to 2 weeks, while the term "late" has been used for periods up to 3 months post-injury. ${ }^{3}$ Comprehensive rehabilitation after PF is required as early as possible. To the best of our knowledge there are no reviews considering rehabilitative interventions in patients with $\mathrm{PF}$, thus we aim to give an overview of important topics of PF rehabilitation. Based on literature evidences and expert opinions, key topics were collated to generate advices and recommendations for daily practice.

\section{Materials and Methods}

This literature-based update was focused on the following research questions that were defined by a panel of physiatrists and orthopaedic surgeons:
1. Main associated traumatic injuries and complications of PF;

2. Management of complex fractures of the pelvis, in the early and late post-trauma period;

3. Start of rehabilitation in PF

4. Treatment of patients who do not undergo surgery;

5. Associated peripheral nerves damages;

6. Associated bladder disorders, urinary incontinence, anorectal, bowel and sexual disfunctions.

A comprehensive literature research was conducted using MEDLINE, EMBASE, and the Cochrane Database of Systematic reviews. Inclusion Criteria: abstracts in English, published between January 1980 to May 2020, found using the primary search strategy and the following key words combined with AND/OR: PF, associated injuries, management, rehabilitation, nerve injury, nerve lesion, bladder disorder, urinary incontinence, anorectal disorder, bowel dysfunction, sexual dysfunction. Search restrictions were imposed to exclude age group patients under the age of 18. Published abstracts of case report, small and large case series, clinical trials, randomized controlled trials, prospective and retrospective observational studies, multicenter studies, systematic reviews, meta-analysis and guidelines were included. 


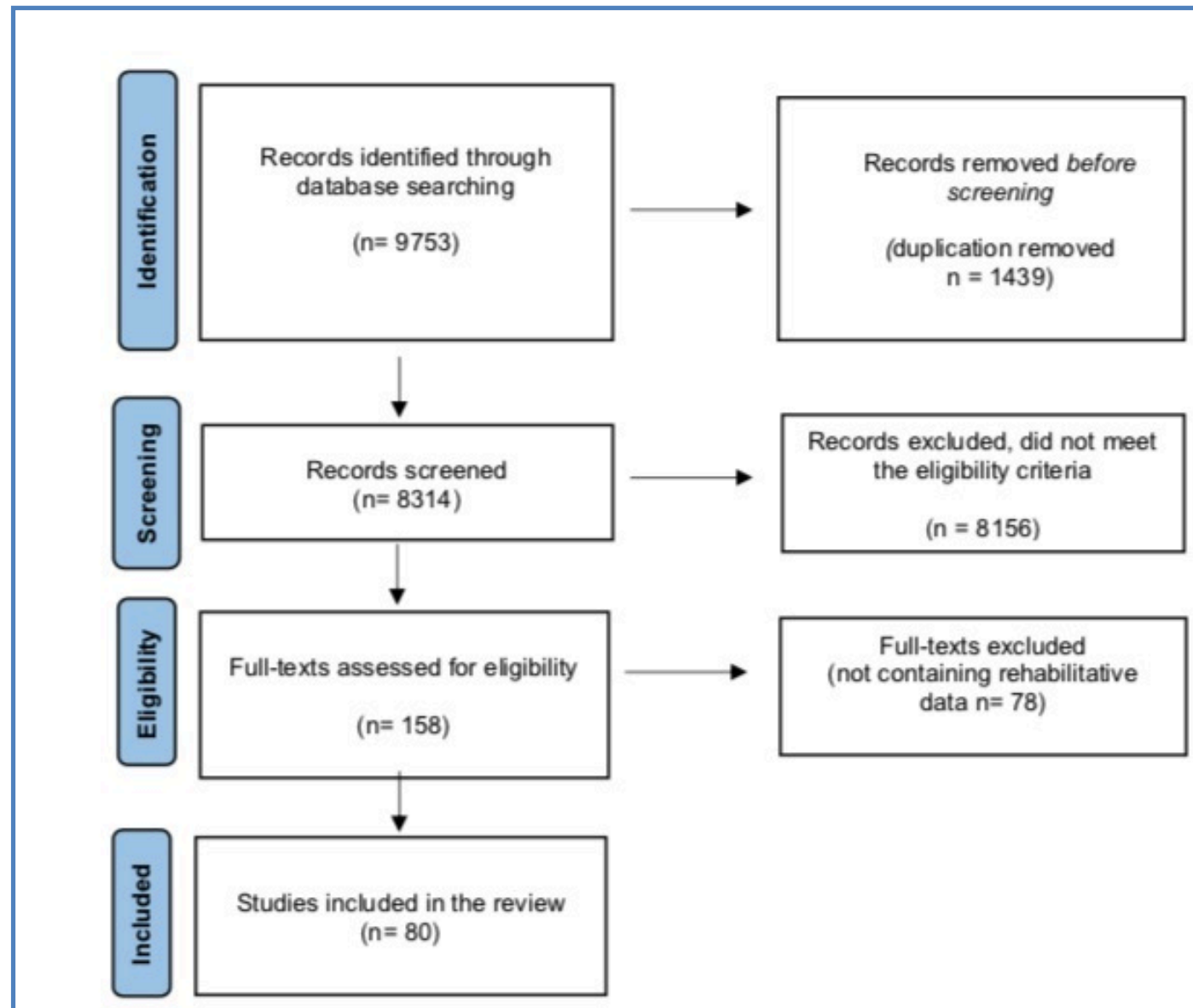

Fig 1. PRISMA flow diagram of studies selection for review

The abstracts of all articles matching the search strategy were reviewed and full-text versions of suitable articles were obtained. It was then checked whether these articles could contribute to answering the research questions. If so, their reference lists were hand-searched for further relevant literature, which was then also added to the final list of articles. The methodology for studies selection is summarized in Figure 1.

This review covers the following grading of the quality of literature: high quality: randomized controlled trials, meta-analysis of randomized controlled trials; moderate quality: not randomized trials, prospective cohort studies; low quality: retrospective observational, retrospective cohort, and case-control studies; very low quality: case series, case reports, reviews, other. Some designs did not fit into this scheme and were graded individually.

\section{Results}

The literature search produced a total of 9753 papers with abstracts. Among these, 158 papers were finally considered for eligibility and 80 papers were finally included in the review.

In severe pelvic injuries, there is an $80 \%$ chance of associated other intrapelvic lesions, ${ }^{4,5}$, thoracoabdominal injuries like ribs or stern fractures, pneumothorax, liver laceration, and splenic rupture, small or large intestine lesions, ${ }^{6,7}$ and other local lesion involving soft tissues (over $72 \%$ of patients), rectum and sphincters (18 - 64\%), urethra (1,6 - $25 \%)$, bladder (neurogenic bladder, structural rupture), vagina, nerves, ${ }^{8}$ as well as post-traumatic osteoarthritis $(7-40 \%)^{9}$, heterotopic ossification, ${ }^{10,11}$ and ischemic necrosis of the femoral head. ${ }^{9}$ Pelvic ring and acetabular fractures often present with perineal swelling of soft tissue, due to the hemorrhage that develops into the retroperitoneal space and flows dissecting fascial planes into the scrotum. ${ }^{12}$ It has been reported malfunction of micturition in $7.6 \%$ of male patients, and sexual malfunction with erectile dysfunction in 11.6\%; dyspareunia has been reported in $2.2 \%$ of female patients. ${ }^{13}$ Nerve lesions are quite common in PF, associated in particular with acetabular fractures of the posterior wall. ${ }^{14}$ Most frequent nerve injuries are sciatic nerve lesions. Lumbosacral plexopathy, as lumbo-sacral plexus avulsion, is another peripherical nervous system lesion associated with PF (from 0,6 \%) ${ }^{15,16}$ and is more frequent as fracture sites number and instability increase. ${ }^{17}$ If evaluated with electrodiagnostic tests, lumbosacral plexopathy is present in a higher number of patients (about 31\%). ${ }^{17}$ In patients affected by severe $\mathrm{PF}$, surgical treatment with internal fixation needs to be done as soon as possible because prolonged time to operative fixation leads to 
worst functional outcome. ${ }^{3}$ There is general consensus that posterior pelvic ring fractures or vertical or rotational instability require surgical fixation. ${ }^{8}$

After the trauma, the "early fixation" definition, varies across studies from 8 hours up to 2 weeks. ${ }^{3}$ The definitive fixation should be performed from the fourth day after the trauma, as soon as the general condition of the patients allows to do it. ${ }^{3}$ In the acute phase, it is important to use a pelvic binder in its correct placement ${ }^{18}$ for suspected pelvic injury before imaging is available. ${ }^{19} \mathrm{~A}$ multidisciplinary approach is needed to treat properly patients with open PF and to obtain the best outcomes. ${ }^{10}$ In case of active external hemorrhage, emergency surgery and transcatheter arterial embolization are used to gain definitive hemostasis. ${ }^{20}$ In patients with high probability of concomitant external and internal hemorrhage, early transcatheter arterial embolization should be considered. ${ }^{20}$ Pelvic inlet, outlet and lateral radiographs are recommended after a pelvis fractures to properly observe the sacrum. ${ }^{21}$ Sacral fractures could cause instability of pelvic ring; internal fixation promotes healing of the fracture. Healing could require up to 12 weeks whereby the patient is advised to avoid weight bearing activities predisposing to immobility. It is important to understand when partial weight-bearing is allowable, monitoring the fracture while healing, ${ }^{22}$ in order to avoid unnecessary muscle degradation. Nowadays non operative treatment, that has been the first choice in the past for sacral fracture, is suited for patients without neurologic deficits and with angulated or minimally displaced fractures. ${ }^{21}$ However, the U-shaped sacral fractures, an uncommon type of PF associated with neurological injury, must be treated properly to avoid progressive deformity and chronic pain. ${ }^{7}$

There is a diffuse consensus about a non-weight-bearing period after surgical fixation of acetabular and PF, in which patients can start an early passive mobilization protocol in bed and chair after 15 days. ${ }^{7}$ The most acceptable indication of the postoperative management of $\mathrm{PF}$, according to the AO Principles of Fracture Management, consists of a non-weight bearing period of 6 to 12 weeks, followed by a progressive increase in weight load of about $25 \%$ every week. ${ }^{23}$ Active rehabilitation is then initiated, and transfer and exercise training can begin after 45 days. There is some evidence about permissive weight bearing protocols based on patient's perception of pain, redness or swelling at the site of the fracture or feeling of instability. ${ }^{7}$ To reduce the hospitalization time, it is important to determine when the fracture is stable enough to consent partial weight bearing. To assess the healing of the fractures, different techniques have been evaluated, among which conventional radiology is still the most used. ${ }^{22}$ In a study on unstable PF, after surgical treatment, the healing time for PF was between 12 and 18 weeks, while for acetabular fractures it was between 12 and 22 weeks. ${ }^{6} \mathrm{~A}$ previous systematic review of multidisciplinary rehabilitative interventions in patients with multiple trauma $^{24}$ and a recent paper highlighted the lack of guidelines for post-surgical rehabilitation in PF. ${ }^{25}$ Early rehabilitation of the patient with PF may begin with prevention strategies, principally of skin ulcers, loss of Range of Movement (ROM), joint contractures and urogenital disorders. If allowed, patient's position should be changed every 2-3 hours with semisupine position and right and left side lying and low-air-loss bed must be used in patients with unstabilized fractures. ${ }^{26}$ Preventing hip flexors and/or knee flexors shortening through proper positioning and daily ROM exercises can help to achieve standing and ambulation recovery when permitted. ${ }^{27}$ The rehabilitation short-term goals include partial independence through transfers and wheelchair mobility, achieved from 2 to 6 weeks, depending on the subjects' medical status. ${ }^{28}$ Transfer training is accomplished with or without a sliding board. If there are also upper extremity or trunk injuries, some assistance may be needed. ${ }^{29}$ The exercise program includes basic ROM and strengthening exercises to prevent contracture and reduce atrophy, isometric exercises (e.g., gluteal or quadriceps femoris muscle sets), and upper-extremity resistive exercises (e.g., shoulder and elbow flexion and extension) performed until fatigue. Gentle active assisted exercises can be performed in patients having difficulty with full active ROM. Ideally, the patients should perform the entire exercise program without assistance before the discharge from hospital. Once weight bearing is resumed, physical therapy consists of gait training and resistive exercises for the trunk and extremities, along with cardiovascular training (e.g. treadmill or exercise bicycle training). Aquatic therapy can be used when available. $^{30}$

According to the AO surgery reference, ${ }^{31}$ nonoperative treatment (traction) of unstable pelvic ring injuries is reserved for patients who cannot undergo surgery. Traction is maintained until there is $\mathrm{X}$-ray evidence of healing (typically up to 3 months). A personalized mobilization program is allowed after the period of traction and exercises to avoid stiffness and promote muscle function are advisable even in a bed bound patient. Patients should be followed for one year to assess outcomes and maintenance of reduction. ${ }^{31}$ Stable PF do not require operative treatment. For these patients, weight bearing must be individualized but initial protection, using crutches or a walker, gradually decreased as comfort and healing permit, is advocated. ${ }^{31}$ Most PF become increasingly stable by 6 weeks from the acute event and are healed by 3 months. The AO assumes that a possible approach can be to allow the patient to bear weight according to tolerance. ${ }^{31}$

The prevalence rate of nerve structural injuries associated with pelvic and acetabular fracture is between 5 and 25 $\%{ }^{14}$ In PF, it has been found a correlation between the fracture type of Tile classification and the rate of nervous injury. The rate of neurological dysfunction rises from $1,5 \%$ in type A fractures to $14 \%$ in type C fractures. ${ }^{32}$ Among the acetabular ones, fractures of posterior wall of 
the acetabulum are most associated with motor nerve structural damage. ${ }^{14}$ Acetabular fractures of the posterior wall were also found to be more associated with nerve injuries at hospital discharge than other acetabular fractures. ${ }^{33}$ Patients with complex PF with soft tissue or pelvic organ injuries suffer from significantly more neurological dysfunctions (33.5\%). ${ }^{34}$ In case of clinical suspicion of nerve injury, neurophysiological tests should be performed to quantify the damage and obtain prognostic information. ${ }^{34}$ Electromyography is the most useful test. ${ }^{35}$ Incomplete nerve lesions restore with a better prognosis than complete ones with loss of sensation usually recovering better than motor deficits. ${ }^{14}$ In PF, the roots L5, S1 and peripheral nerves were identified as the most endangered anatomical regions. ${ }^{32}$ Intraoperative injuries have worst prognostic outcome than neurological lesions made by trauma itself. ${ }^{14}$ Certain types of acetabular fractures and operative surgery can be associated with superior gluteal neurovascular damage. Extended posterior approach seems to be useful to reduce superior gluteal neurovascular damage rate. ${ }^{36}$ In operatively treated acetabular fractures, peripheral neurologic injury occurs most commonly in sciatic nerve distribution. ${ }^{37,38}$ Neurologic deficit of sciatic nerve after acetabular fractures could be identified as preoperative (57\%), iatrogenic (19\%, with a presentation immediately after surgical treatment), and postoperative (24\%) related to implant migration, muscular scarring, or heterotopic ossifications. ${ }^{37,38}$ A root distribution of nerve lesions in patients with acetabular factures has been described as follow: L2-L3: 3,7\%, L4: 9,6\%, L5: 60,9\%, S1: 25,6\%. About the $34 \%$ of patients with these neurological lesions had no recover, $37 \%$ had a partial recover while $29 \%$ had a complete recover. Among all iatrogenic lesions, about $55 \%$ do not recover. ${ }^{37}$ There is evidence that operative maneuvers and operative reduction of acetabulum fractures can compromise functional integrity of distal sciatic nerve. Somatosensory evoked potentials from the tibial and fibular nerves during operative treatments could be useful to identify and monitoring these disfunctions. ${ }^{8,38}$ Kocher-Langenbeck operative approach seems to lead to a higher risk of perioperative nerve injuries than other operative fixation methods. ${ }^{39}$ Operative INFIX fixation leads to a higher incidence of femoral nerve damage while mini-invasive stabilization of pelvic ring seems not to increase the risk of nerve injury. ${ }^{14}$ In a retrospective cohort study in patients treated with the Stoppa approach, it has been reported an obturator nerve injury rate after acetabular fracture of $9.1 \%$, as a result from the initial trauma and not from the operative treatment. ${ }^{34}$ The acetabular operative fixation by ileo-inguinal approach has demonstrated high risk of lateral femoral cutaneous nerve lesion, probably due to the traction on the psoas muscle during the retroperitoneal dissection. ${ }^{40,41}$ To reduce this risk, in eligible patients the Stoppa approach can be used ${ }^{4.0}$ According to the classification of Denis of sacral fractures, nerve injury of one of two sides can be obtained in all three types of sacral fracture. If the impact energy is above $25 \mathrm{~J}$, a sacral foramen fracture and nerve root injury can easily occur than lower energy trauma. ${ }^{42}$ In unstable sacral fractures which need operative fixation it was recognized a higher rate of accompanying nerve lesions (15.4\%) than in stable sacral fractures (3.8\%). ${ }^{32}$ Testing of the sacral reflexes assesses the integrity of the sacral spinal cord at S2 to S4 as well as the associated afferent and efferent pathways. ${ }^{43}$ General rules about treatment of nerve injuries can be also useful for PF: open sharp nervous lesions should be treated within 72 hours from acute event while closed lesions are indicated for surgery only if complete denervation remains unchanged for three months after the injury. ${ }^{33}$ After the injury, best recovery results can be achieved within six months. ${ }^{33}$ Nervous irritation made by scarring, bone fragments or iatrogenic injury (clamps, cement, screw, etc.) may be operatively revised later. In a retrospective study of 119 surgical treated femoral nerve lesions, repairs resulted in good functional recovery at the follow-up visit. ${ }^{44}$ In irreversible nerve lesions caused by pelvic and acetabular fractures, surgical muscle transfer can restore the movement. In particular, for palsy of the peroneal division of the sciatic nerve, the transposition of tibialis posterior muscle could be useful. ${ }^{14}$ For peripheral nerve injuries Therapeutic Electrical Muscle stimulation may be helpful in preserving the contractility and extensibility of denervated muscle tissue and in retarding muscle atrophy until reinnervation is established. ${ }^{45,46}$ The stimulation program should be continued for 2 to 6 weeks after the time predicted for complete reinnervation. Once voluntary active contraction is resumed, physical therapy, consisting of isometric exercises, should be continued. ${ }^{47}$

Urinary disfunction seems to be frequent among pelvis fractures patients (41\%). There is a high occurrence of micturition disorder in middle-aged woman after pelvis fractures. ${ }^{48}$ These problems should be looked for early during the period of pelvis fractures treatment by a specialist in urology or gynecology. ${ }^{48,49}$ In males, voiding and sexual dysfunction after pelvic fracture posterior urethral injury are probably the results of injury itself, not of the immediate treatment modalities. ${ }^{50}$ Urodynamic test like flow cystometry, uroflowmetry and urethral pressure profile at rest are commonly used to evaluate urination disorders. ${ }^{48}$ Overactive bladder syndrome is a frequent complication in PF (18,9\%), especially in unstable $\mathrm{PF}$ (24.8\%), and it seems to be due by many factors as development of pelvic hematoma and damage of pelvic diaphragm. ${ }^{51}$

Appropriate management of the bladder is of primary importance to ensure that it does not distend and overstretch the tight junctions, leading to irreversible damage. Irrespective of the management approach, patients with neurological bladder dysfunction will often have a concurrent urinary tract infection (UTI) and, therefore, urine analysis and urine culture should routinely be performed. Routine antibiotic 'cover' is not 
recommended, as it predisposes to resistant infections. Residual urine volume should be checked periodically by ultrasound or catheterization, as large residual volumes will predispose to UTIs. If continence is not regained within a few days, indwelling catheterization can provide further time for improvement and prevent UTI in the short term. Intermittent catheterization (every 4-6 h) is associated with a lower risk of UTI in the long term than an indwelling catheter. ${ }^{52,53}$ Possible treatments to reduce overactive bladder are surgical stabilization and pharmacologic therapy with M-cholinoblockers and $\alpha 1$ blockers. Sacral and pudendal neuromodulation could be a treatment in patients with traumatic urinary retention after pelvis fractures to recover a proper voiding. ${ }^{54}$ Depending on the extent of the lesion, in some patients, pelvic floor exercises, electrical stimulation or biofeedback may help to restore some pelvic floor function: exercises may improve the strength of the pelvic floor muscles once there is some return of function. ${ }^{55}$

Type C-type fractures are more associated with intestinal and defecation problems than B-type (75\% versus $52 \%) .{ }^{56}$ Regarding paralytic ileus after trauma, a direct correlation between type of pelvic fracture, amount of retroperitoneal blood and duration of paralytic ileus has been documented. ${ }^{57,58}$ In neurogenic bowel, colonic transit can be delayed with constipation, fecal impaction, abdominal distention and bloating incontinence. During treatment periods, evacuation diary cards should be used to report symptoms related to abdominal discomfort, need of digital maneuvers, time of defecation $>1$ hour, etc. Patients should be treated by increasing fluid intake and dietary fibers, and using suppositories, fleets enemas, and laxatives. Pelvic floor exercises, electrical stimulation or biofeedback may be an adjunct to these treatments. ${ }^{52}$ Contrast enema and Computed tomography (CT) abdominal and pelvic scan are commonly used as diagnostic tools in PF related bowel injury. ${ }^{52,59}$ At 1 year follow up after pelvis fractures, the prevalence of bowel incontinence has been reported of $8 \%$ with decreased quality of life. ${ }^{59}$ Functional testing, such as colonic transit testing after ingestion of radiopaque markers, manometry, and defecography may provide functional assessment of the lower gastrointestinal tract and its neural control. ${ }^{52}$

A quarter of genito-urinary injuries are caused by PF; erectile dysfunction (ED) is frequently associated with type $C$ fractures, ${ }^{60-62}$ symphysis pubis, ${ }^{61,63-65}$ or sacroiliac joints diastasis, ${ }^{61}$ bilateral pubic ramus fractures, ${ }^{61,66}$ and even more in fractures with urethral injury. ${ }^{61,67-69}$ Among patients with neural abnormalities, impaired function was found in bulbocavernosus reflex (76\%), pudendal nerve (30\%) and posterior tibial somatosensory nerve (37\%). ${ }^{70}$ Overall, the most important causes seem to be the disruptions of the cavernous nerves, ${ }^{66,69,71,72}$ lateral to the prostatomembranous urethra. ${ }^{66,71}$ Diagnosis of ED and its cause may be achieved with nocturnal penile tumescence testing, penile duplex ultrasound and neurophysiological testing. ${ }^{70}$ In addition, penile duplex ultrasound with intracavernous injection may be performed. ${ }^{70,71}$ Magnetic resonance imaging may help in the assessment of the damage extent. ${ }^{71}$ The treatment of erectile dysfunction may be based on oral phosphodiesterase type 5 inhibitors (PDE5i) as first treatment, ${ }^{67}$ because this approach is usually effective, well-tolerated, and non-invasive. ${ }^{72}$ It should be administered daily at low dose, ${ }^{73,74}$ and should be started as soon as possible. ${ }^{75}$ In patients in which PDE5i treatment is not effective, low-intensity shock wave therapy may reduce the symptoms of ED, ${ }^{67,76}$ and ameliorate PDE5i response. ${ }^{67}$ It may be effective also on chronic prostatitis and chronic pelvic pain syndrome. ${ }^{76}$ Other approaches, depending on the main cause of the $\mathrm{ED}$, may be intracavernosal injections of prostaglandin $\mathrm{E} 1,{ }^{72,77}$ and inflatable penile prostheses. ${ }^{77}$ Sexual problems are more frequent in female affected by C-type fractures, too. PF may be associated to genitourinary and anal sphincter injuries, ${ }^{78-80}$ prolapse, ${ }^{80}$ dyspareunia, ${ }^{78,80,81}$ and persistent local pain. ${ }^{80}$ Female urethral injuries are rare, ${ }^{82} 83$ and can vary form urethral contusion to circumferential rupture. ${ }^{82}$ Vaginal trauma may be associated. ${ }^{83}$ Vaginal injury has low incidence in pelvic ring fractures. ${ }^{78}$

\section{Discussion}

Overall, considering all papers independently from the quality, the topics that were more studied in literature were associated bladder urinary disorders and incontinence, associated anorectal and bowel disfunctions, and associated sexual disfunctions in male. On the other hand, the timing to start rehabilitation was poorly studied (only 5 papers). If we consider the quality of the papers in the single questions, high quality studies were found only regarding associated traumatic injuries and complications of PF and the management of complex fractures of the pelvis in the post trauma period (one per type). For the same topics, also moderate quality studies were found (respectively 4 and 2). Moderate quality studies were found in the other topics, especially regarding sexual disfunction in male (15 studies of moderate quality). For the other questions, the majority of references were low or very low quality studies. Concerning management in patients who cannot undergo surgery, only one non classifiable reference was found. To summarize, main advices and recommendations in daily clinical practice for PF rehabilitative management are:

1. In pelvic injuries, it is important to assess associated intrapelvic lesions, that may occur in $80 \%$ of cases; ${ }^{4,5}$

2. In patients affect by severe PF, surgical treatment with internal fixation has to be done as soon as possible because prolonged time to operative fixation leads to worst functional outcome; ${ }^{3}$

3. The most acceptable indication of the postoperative management of PF consists of a non-weight bearing period of 6 to 12 weeks, in which patients can start an early passive mobilization protocol after 15 days. $^{7}$ 
Then, a progressive increase in weight load of about $25 \%$ every week can be started. ${ }^{23}$

4. Nonoperative treatment is reserved to stable PF and unstable pelvic ring injuries in cases in which the patient cannot undergo surgery. After non-operative treatment is completed, patients should be mobilized with physical therapy. ${ }^{31}$

5. In PF, the roots L5, S1 and sciatic nerve were identified as the most endangered anatomical regions. Open sharp nervous lesions should be treated within 72 hours from acute event meanwhile closed lesions are indicated for surgery only if complete denervation remain unchanged three months after the injury. ${ }^{33}$ In irreversible nerve lesions, surgical muscle transfer may restore the movement. ${ }^{14}$ For peripheral nerve injuries Electrical Muscle stimulation may be helpful. ${ }^{44,45}$

6. Bladder lesion and overactive bladder syndrome is a frequent complication in $\mathrm{PF}$, especially in unstable $\mathrm{PF}^{51}$ In patients affected by $\mathrm{PF}$, diagnostic cystourethrogram is considered the gold standard of imaging for lower urinary tract, while urodynamic study can predict the prognosis in postoperative PF patients. $^{48}$

7. C-type fractures are more associated with intestinal and defecation problems than B-type. ${ }^{56}$ Contrast enema, CT abdominal, pelvic scan and functional testing are commonly used as diagnostic tools. ${ }^{59,52}$

8. Erectile dysfunction, frequently associated with Ctype fractures, symphysis pubis or sacroiliac joints diastasis, bilateral pubic ramus fractures, and urethral injury, ${ }^{60-69}$ must be properly treated. In female patients, PF may be associated to genitourinary prolapse, dyspareunia and persistent local pain. ${ }^{78-80}$

In conclusion, this review underlines the lack of highquality evidences for rehabilitation after PF in terms of duration and modality of therapy, types of rehabilitation setting, care pathways, and long-term functional outcomes. However, these results support an early multidisciplinary evaluation and treatment in PF patients. Further studies in PF survivors are needed to build the evidence base for rehabilitative interventions.

\section{List of acronyms}

CT - computed tomography

ED - erectile dysfunction

PDE5i - Phosphodiesterase type 5 inhibitors

$\mathrm{PF}$ - pelvic fracture

ROM - range of movement

UTI - urinary tract infection

\section{Authors contributions}

All Authors: Conception or design of the work; FP, GP, AMC, GR, MCM, Data collection; All Authors: Data analysis and interpretation, drafting, critical revision and final approval of the version to be published.

Acknowledgments None.

\section{Funding}

The authors received no financial support for the research, authorship, and publication of this article.

\section{Conflict of Interest}

The authors declare no competing interests.

\section{Ethical Publication Statement}

We confirm that we have read the Journal's position on issues involved in ethical publication and affirm that this report is consistent with those guidelines.

\section{Corresponding Author}

Maria Chiara Maccarone, Physical Medicine and Rehabilitation School, University of Padova, Via Giustiniani 3, 35128 Padova, Italy

ORCID iD: 0000-0001-6509-5707

E-mail: mariachiara.maccarone93@gmail.com

E-mails and ORCID iD of co-authors

Francesco Piccione: francesco.piccione@aopd.veneto.it ORCID iD: 0000-0002-0173-903X

Anna Maria Cortese: annamaria.cortese@ospedalesancamillo.net

Guido Rocca: guidofly56@gmail.com

Umberto Sansubrino:

umberto.sansubrino@aopd.veneto.it

Giovanni Piran: giovanni.piran@gmail.com

Stefano Masiero: stef.masiero@unipd.it

ORCID iD: 0000-0002-0361-4898

\section{References}

1. Grotz MR, Allami MK, Harwood P, Pape HC, Krettek C, Giannoudis PV. Open pelvic fractures: epidemiology, current concepts of management and outcome. Injury. 2005;36(1):1-13. doi: 10.1016/j.injury.2004.05.029. PMID: 15589906.

2. Yoshihara H, Yoneoka D. Demographic epidemiology of unstable pelvic fracture in the United States from 2000 to 2009: trends and inhospital mortality. J Trauma Acute Care Surg. 2014;76(2):380-5. doi: 10.1097/TA.0b013e3182ab0cde. PMID: 24398776.

3. Sharpe JP, Magnotti LJ, Gobbell WC, Huang X, Perez EA, Fabian TC, Croce MA. Impact of early operative pelvic fixation on long-term self-reported outcome following severe pelvic fracture. J Trauma Acute Care Surg. 2017;82(3):444-450. doi:10.1097/TA.0000000000001346

4. Rommens PM. Pelvic ring injuries: a challenge for the trauma surgeon. Acta Chir Belg. 1996;96(2):7884.

5. Wilker DK, Izbicki JR, Euler E, Schweiberer L. Verletzungen des Beckens und der Retroperitonealorgane [Injuries of the pelvis and retroperitoneal organs]. Urologe A. 1991;30(3):183-188. 
6. Phruetthiphat OA, Willey M, Karam MD, Gao Y, Westerlind BO, Marsh JL. Comparison of Outcomes and Complications of Isolated Acetabular Fractures and Acetabular Fractures With Associated Injuries. J Orthop Trauma. 2017;31(1):31-36. doi:10.1097/BOT.0000000000000720

7. Gribnau AJ, van Hensbroek PB, Haverlag R, Ponsen KJ, Been HD, Goslings JC. U-shaped sacral fractures: surgical treatment and quality of life. Injury. 2009;40(10):1040-1048. doi:10.1016/j.injury.2008.11.027

8. Coccolini F, Stahel PF, Montori G, et al. Pelvis fractures: WSES classification and guidelines. World J Emerg Surg. 2017;12:5. doi:10.1186/s13017-017-0117-6

9. Cai L, Lou Y, Guo X, Wang J. Surgical treatment of unstable pelvic fractures with concomitant acetabular fractures. Int Orthop. 2017;41(9):18031811. doi:10.1007/s00264-017-3532-0

10. Ruesch PD, Holdener H, Ciaramitaro M, Mast JW. A prospective study of surgically treated acetabular fractures. Clin OrthopRelat Res. 1994;(305):38-46.

11. Meys G, Kalmet PHS, Sanduleanu S, et al. A protocol for permissive weight-bearing during allied health therapy in surgically treated fractures of the pelvis and lower extremities. J Rehabil Med. 2019;51(4):290-297. doi:10.2340/16501977-2532

12. Raman R, Senior C, Segura P, Giannoudis PV. Management of scrotal swelling after pelvic and acetabular fractures. Br J Nurs. 2004;13(8):458461. doi:10.12968/bjon.2004.13.8.12782

13. Pohlemann $\mathrm{T}$, Tscherne $\mathrm{H}$, Baumgärtel $\mathrm{F}$, et al. Beckenverletzungen: Epidemiologie, Therapie und Langzeitverlauf. Ubersichtüber die multizentrischeStudie der ArbeitsgruppeBecken [Pelvic fractures: epidemiology, therapy and longterm outcome. Overview of the multicenter study of the Pelvis Study Group]. Unfallchirurg. 1996;99(3):160-167.

14. Čižmář I, Vlček M, Ehler E, Dráč P. Rekonstrukce paréz dolní končetiny po zlomeninách pánve svalovými transfery [Reconstruction of Lower Extremity Palsy after Pelvic Fractures with the Muscle Transfers]. Acta Chir Orthop Traumatol Cech. 2019;86(5):348-352.

15. Chiodo A. Neurologic injury associated with pelvis fractures: radiology and electrodiagnosis evaluation and their relationships to pain and gait outcome. Arch Phys Med Rehabil. 2007;88(9):1171-1176. doi:10.1016/j.apmr.2007.06.004

16. Cakmak A. Electrical stimulation of denervated muscles. Disabil Rehabil. 2004;26(7):432-433. doi:10.1080/09638280410001663157

17. Jang DH, Byun SH, Jeon JY, Lee SJ. The relationship between lumbosacral plexopathy and pelvic fractures. Am J Phys Med Rehabil.
2011;90(9):707-712.

doi:10.1097/PHM.0b013e31821f6bd9

18. Fleiter $\mathrm{N}$, Reimertz $\mathrm{C}$, Lustenberger $\mathrm{T}$, Schweigkofler U, Marzi I, Hoffmann R, Walcher F. Bedeutung der korrekten Positionierung eines Beckengurts zur temporären Stabilisierung von Beckenringverletzungen [Importance of the correct placement of the pelvic binder for stabilisation of haemodynamically compromised patients]. Z Orthop Unfall. 2012;150(6):627-629. doi:10.1055/s-0032-1327796

19. Hsu SD, Chen CJ, Chou YC, Wang SH, Chan DC. Effect of Early Pelvic Binder Use in the Emergency Management of Suspected Pelvis fractures: A Retrospective Cohort Study. Int J Environ Res Public Health. 2017;14(10):1217. doi:10.3390/ijerph14101217

20. Fu CY, Huang RY, Wang SY, Liao CH, Huang JF, Hsu YP, Lin CY, Kang SC. Concomitant external and internal hemorrhage: Challenges to managing patients with open pelvic fracture. Am J Emerg Med. 2018;36(11):1937-1942. doi:10.1016/j.ajem.2018.02.014

21. Yi C, Hak DJ. Traumatic spinopelvic dissociation or U-shaped sacral fracture: a review of the literature. Injury. 2012;43(4):402-408. doi:10.1016/j.injury.2010.12.011

22. Wong LC, Chiu WK, Russ M, Liew S. Review of techniques for monitoring the healing fracture of bones for implementation in an internally fixated pelvis. Med Eng Phys. 2012;34(2):140-152. doi:10.1016/j.medengphy.2011.08.011 F

23. Ruedi T. AO principles of fracture management. New York: Thieme; 2007.

24. Khan F, Amatya B, Hoffman K. Systematic review of multidisciplinary rehabilitation in patients with multiple trauma. Br J Surg. 2012;99 Suppl 1:88-96. doi:10.1002/bjs.7776

25. Meys G, Kalmet PHS, Sanduleanu S, van Horn YY, Maas GJ, Poeze M, Brink PRG, Seelen HAM. A protocol for permissive weight-bearing during allied health therapy in surgically treated fractures of the pelvis and lower extremities. J Rehabil Med. 2019;51(4):290-297. doi:10.2340/16501977-2532

26. Bergstrom N, Bennet MA, Carlson et al.: pressure ulcer treatment clinical practice guideline. Quick reference guide for clinicians, No 15, Rockville, MD, US Department of health and human service. Agency for health care policy and research. AHCPR publication No 95-0653. December 1994.

27. Szulc P. Impact of Bone Fracture on Muscle Strength and Physical Performance-Narrative Review. Curr Osteoporos Rep. 2020;18(6):633645. doi:10.1007/s11914-020-00623-1

28. Rice LA, Ousley C, Sosnoff JJ. A systematic review of risk factors associated with accidental falls, outcome measures and interventions to manage fall risk in non-ambulatory adults. Disabil Rehabil. 
2015;37(19):1697-705. doi:10.3109/09638288.2014.976718.

29. Milner-Brown HS, Miller RG. Muscle strengthening through high-resistance weight training in patients with neuromuscular disorders. Arch Phys Med Rehabil. 1988;69(1):14-19.

30. Cup EH, Pieterse AJ, Ten Broek-Pastoor JM, Munneke M, van Engelen BG, Hendricks HT, van der Wilt GJ, Oostendorp RA. Exercise therapy and other types of physical therapy for patients with neuromuscular diseases: a systematic review Arch Phys Med Rehabil 2007;88:1452-64

31. AO Foundation. 2014. Available from: www.aofoundation.org

32. Schmal H, Hauschild O, Culemann U, Pohlemann T, Stuby F, Krischak G, Südkamp NP. Identification of risk factors for neurological deficits in patients with pelvic fractures. Orthopedics. 2010;33(8):10.3928/0147744720100625-13. doi:10.3928/01477447-20100625-13

33. Kaiser R. Chirurgická léčba poranění nervů dolních končetin [Surgical treatment of lower extremity peripheral nerve injuries]. Cas Lek Cesk. 2016;155(3):16-20.

34. Kim JW, Shon HC, Park JH. Injury of the obturator nerve in the modified Stoppa approach for acetabular fractures. Orthop Traumatol Surg Res. 2017;103(5):639-644. doi:10.1016/j.otsr.2017.03. 005

35. Conway RR, Hubbell SL. Electromyographic abnormalities in neurologic injury associated with pelvic fracture: case reports and literature review. Arch Phys Med Rehabil. 1988;69(7):539-541

36. Studer P, Kosuge D, Rickman M, Solomon LB. Versatility of an Extended Posterior Approach for the Treatment of Acetabular Fractures With Reference to the Superior Gluteal Neurovascular Bundle. J Orthop Trauma. 2016;30(8):e289-e293. doi:10.1097/BOT.0000000000000545

37. Bogdan Y, Tornetta P 3rd, Jones C, Gilde AK, Schemitsch E, Vicente M, Horwitz D, Sanders D, Firoozabadi R, Leighton R, de Dios Robinson J, Marcantonio A, Hamilton B. Neurologic Injury in Operatively Treated Acetabular Fractures. J Orthop Trauma. 2015;29(10):475-478. doi:10.1097/BOT.0000000000000362

38. Beaulé PE, Antoniades J, Matta JM. Trans-sacral fixation for failed posterior fixation of the pelvic ring. Arch Orthop Trauma Surg. 2006;126(1):4952. doi:10.1007/s00402-005-0069-2

39. Lehmann W, Hoffmann M, Fensky F, Nüchtern J, Großterlinden L, Aghayev E, Lehmann H, Stuby F, Rueger JM. What is the frequency of nerve injuries associated with acetabular fractures?. Clin Orthop Relat Res. 2014;472(11):3395-3403. doi:10.1007/s11999-014-3838-9

40. Lao A, Putman S, Soenen M, Migaud H. The ilioinguinal approach for recent acetabular fractures: ultrasound evaluation of the ilio-psoas muscle and complications in 24 consecutive patients. Orthop Traumatol Surg Res. 2014;100(4):375-378. doi:10.1016/j.otsr.2014.02.006

41. Mirovsky Y, Neuwirth M. Injuries to the lateral femoral cutaneous nerve during spine surgery. Spine (Phila Pa 1976). 2000;25(10):1266-1269. doi:10.1097/00007632-200005150-00011

42. Quan RF, Yang DS, Wang YJ. Study of the morphology and biomechanics of sacral fracture. Chin J Traumatol. 2006;9(5):259-265.

43. Kimura J. Electrodiagnosis in diseases of nerve and muscles: principles and practice. Oxoford University Press. 2001.

44. Kim DH, Murovic JA, Tiel RL, Kline DG. Intrapelvic and thigh-level femoral nerve lesions: management and outcomes in 119 surgically treated cases. J Neurosurg. 2004;100(6):989-996. doi:10.3171/jns.2004.100.6.0989

45. Parizotto NA. Is electrical stimulation a consolidated treatment for denervated muscles and functional recovery after nerve injuries?. Muscle Nerve. 2011;43(2):299-300. doi:10.1002/mus.21833

46. Kern H, Salmons S, Mayr W, Rossini K, Carraro U. Recovery of long-term denervated human muscles induced by electrical stimulation. Muscle Nerve. 2005;31(1):98-101.

47. Pieber K, Herceg $M$, Paternostro-Sluga $T$, Schuhfried O. Optimizing stimulation parameters in functional electrical stimulation of denervated muscles: a cross-sectional study. J Neuroeng Rehabil. 2015;12:51.

48. Džupa V, Otčenášek M, Vránová J, Ducháč V, Grill R, Báča V. Mikční, sexuální a defekační problémy $\mathrm{u}$ žen $\mathrm{v}$ aktivním věku po zlomenině pánve: srovnávací studie [Micturition, sexual and defecation disorders in middle-aged women after pelvic fractures. A comparative study]. Acta Chir Orthop Traumatol Cech. 2012;79(3):263-268.

49. Odutola AA, Sabri O, Halliday R, Chesser TJ, Ward AJ. High rates of sexual and urinary dysfunction after surgically treated displaced pelvic ring injuries. Clin Orthop Relat Res. 2012;470(8):21732184. doi:10.1007/s11999-012-2257-z

50. Aşci R, Sarikaya S, Büyükalpelli R, Saylik A, Yilmaz AF, Yildiz S. Voiding and sexual dysfunctions after pelvic fracture urethral injuries treated with either initial cystostomy and delayed urethroplasty or immediate primary urethral realignment. Scand J Urol Nephrol. 1999;33(4):228-233. doi:10.1080/003655999750015826

51. Neymark AI, Voytenko AN, Bondarenko AV, Muzalevskaya NI, Kruglykhin IV. Urologiia. 2015;(5):38-42.

52. Umphred DA (ed): Neurological Rehabilitation, 3rd ed. St Louis, Mosby, 1995 
53. Fantl JA, Newman DK, Colling J, et al. Managing acute and chronic urinary incontinence. U.S. Department of Health and human services. J Am Acad Nurse Pract. 1996;8(8):390-403. doi:10.1111/j.1745-7599.1996.tb00681.x

54. White CE, Hsu JR, Holcomb JB. Haemodynamically unstable pelvic fractures. Injury. 2009;40(10):1023-1030. doi:10.1016/j.injury.2008.11.023

55. Bø K, Talseth T, Holme I. Single blind, randomised controlled trial of pelvic floor exercises, electrical stimulation, vaginal cones, and no treatment in management of genuine stress incontinence in women. BMJ. 1999;318(7182):487-493. doi:10.1136/bmj.318.7182.487

56. Weems WL. Management of genitourinary injuries in patients with pelvic fractures. Ann Surg. 1979;189(6):717-723. doi:10.1097/00000658197906000-00007

57. Hurt AV, Ochsner JL, Schiller WR. Prolonged ileus after severe pelvic fracture. Am J Surg. 1983;146(6):755-757. doi:10.1016/00029610(83)90334-3

58. Ashai F, Mam MK, Iqbal S. Ileal entrapment as a complication of fractured pelvis. J Trauma. 1988;28(4):551-552. doi:10.1097/00005373198804000-00026

59. Haj M, Griemberg B, Alkalay I, Stamler B. Large bowel herniation through a central fracture of iliac bone. Isr J Med Sci. 1982;18(2):281-283.

60. El-Assmy A, Harraz AM, Benhassan M, Nabeeh A, Ibrahiem el $\mathrm{H}$. Erectile function after anastomotic urethroplasty for pelvic fracture urethral injuries. Int J Impot Res. 2016;28(4):139-142. doi:10.1038/ijir.2016.18

61. Ceylan HH, Kuyucu E, Erdem R, Polat G, Yılmaz F, Gümüş B, Erdil M. Does pelvic injury trigger erectile dysfunction in men? Chin J Traumatol. 2015;18(4):229-231. doi:10.1016/j.cjtee.2015.04. 004

62. Koraitim MM. Predictors of erectile dysfunction post pelvic fracture urethral injuries: a multivariate analysis. Urology. 2013;81(5):1081-1085. doi:10.1016/j.urology.2012.12.040

63. Mark SD, Keane TE, Vandemark RM, Webster GD. Impotence following pelvic fracture urethral injury: incidence, aetiology and management. $\mathrm{Br} \mathrm{J}$ Urol. 1995;75(1):62-64. doi:10.1111/j.1464-410x.1995. tb07234.x

64. Matthews LA, Herbener TE, Seftel AD. Impotence associated with blunt pelvic and perineal trauma: penile revascularization as a treatment option. Semin Urol. 1995;13(1):66-72.

65. Peng J, Zhang Z, Gao B, Yuan Y, Cui W, Tang Y, Song W, Xin Z. Effect of daily sildenafil on patients with absent nocturnal erections due to pelvic fracture urethral disruption: a single-centre experience. Andrologia. 2016;48(10):1120-1124. doi:10.1111/and.12548

66. Wang CJ, Lu YM, Li CC, Wu WJ, Chien TM. Lowintensity shock wave therapy ameliorates erectile dysfunction in men with pelvic fractures associated with urethral injury. Int $\mathrm{J}$ Impot Res. 2019;31(3):218-222. doi:10.1038/s41443-0180094-7

67. Sangkum P, Levy J, Yafi FA, Hellstrom WJ. Erectile dysfunction in urethral stricture and pelvic fracture urethral injury patients: diagnosis, treatment, and outcomes. Andrology. 2015;3(3):443-449. doi:10.1111/andr.12015

68. Shenfeld OZ, Kiselgorf D, Gofrit ON, Verstandig AG, Landau EH, Pode D, Jordan GH, McAninch JW. The incidence and causes of erectile dysfunction after pelvic fractures associated with posterior urethral disruption. J Urol. 2003;169(6):2173-2176.

doi:10.1097/01.ju.0000067660.51231.05

69. Johnsen NV, Kaufman MR, Dmochowski RR, Milam DF. Erectile Dysfunction Following Pelvic Fracture Urethral Injury. Sex Med Rev. 2018;6(1):114-123. doi:10.1016/j.sxmr.2017.06.004

70. Tang YX, Jiang XZ, Tan J, Huang K, Tang J. Zhong Nan Da XueXue Bao Yi Xue Ban. 2004;29(4):478493.

71. da Silva Gaspar SR, Ferreira ND, Oliveira T, Oliveira P, Dias JS, Lopes TM. Magnetic Resonance Imaging and Pelvic Fracture Urethral Injuries. Urology. 2017;110:9-15. doi:10.1016/j.urology.2017.06.041

72. Machtens S, Gänsslen A, Pohlemann T, Stief CG. Erectile dysfunction in relation to traumatic pelvic injuries or pelvic fractures. BJU Int. 2001;87(5):441-448. doi:10.1046/j.1464410x.2001.02147.x

73. Nieto-Esquivel A, Delgado-Balderas R, RoblesTorres JI, Gómez-Guerra LS. Uso de tadalafilo en la rehabilitación de pacientes con antecedente de lesión de uretra posterior en el contexto de fractura pélvica [Use of tadalafil in the rehabilitation of patients with a history of posterior urethral injury in the context of pelvic fracture]. Rev Int Androl. 2018;16(1):15-19. doi:10.1016/j.androl.2017.02.004

74. Tang YX, Gan Y, Zhang XB, Zhu XS, Jiang XZ, He LY, Yang JF. Zhonghua Nan KeXue. 2013;19(6):539-541.

75. Hong Q, Cui WS, Gao B, Song WD, Xin ZC. Zhonghua Nan KeXue. 2013;19(5):443-445.

76. Xin Z, Lin G, Lei H, Lue TF, Guo Y. Clinical applications of low-intensity pulsed ultrasound and its potential role in urology. Transl Androl Urol. 2016;5(2):255-266. doi:10.21037/tau.2016.02.04

77. Chung PH, Gehring C, Firoozabadi R, Voelzke BB. Risk Stratification for Erectile Dysfunction After 
Pelvic Fracture Urethral Injuries. Urology. 2018;115:174-178.

doi:10.1016/j.urology.2018.01.035

78. Li P, Zhou D, Fu B, Song W, Dong J. Management and outcome of pelvic fracture associated with vaginal injuries: a retrospective study of 25 cases. BMC Musculoskelet Disord. 2019;20(1):466. doi:10.1186/s12891-019-2839-y

79. Aggarwal A, Pandey S, Singh V, Sinha RJ. Posttraumatic bony impingement into vagina: a rare cause of urethrovaginal fistula. BMJ Case Rep. 2018;2018:bcr2018226004. doi:10.1136/bcr-2018226004.

80. Goswami D, Kochhar PK, Suri T, Zutshi V, Batra S. Obstetric and gynecological outcome in a patient with traumatic pelvic fracture and perineal injuries. J Obstet Gynaecol Res. 2012;38(8):1118-1123. doi:10.1111/j.1447-0756.2011.01838.x.
81. Nambiar M, Heaton SR, Stevenson AJ, Bucknill AT. Prominent metalware from pelvic surgery causing dyspareunia. BMJ Case Rep. 2017;2017:bcr2016217285. doi:10.1136/bcr-2016217285.

82. Podestá ML, Jordan GH. Pelvic fracture urethral injuries in girls. J Urol. 2001;165(5):1660-1665.

83. Mevel O, Tahan H, Michel F. Rupture de l'urèthre féminin au cours des fractures du bassin: à propos de deux observations [Rupture of the female urethra in pelvic fractures: report of 2 cases]. Prog Urol. 2000;10(6):1212-1216.

Submission: June 23, 2021 Accepted for publication: August 15, 2021 